\title{
Dengue Virus O utbreak in the Year 2006 at a Tertiary Care Centre in Sindh
}

\section{H anif Ghani, M ona H umaira, Imdad A. Khushk, Asam Ażz Ghouri, Yasmeen Memon and Mohammad Anwer Memon}

\begin{abstract}
OBJECTIVE: To investigate the outcome of 116 patients with suspected / confirmed diagnosis of Dengue fever at our tertiary care setup.

DESIGN: A descriptive study

SETTING: Liaquat University Hospital Hyderabad / Jamshoro. Study was carried out between October and December 2006.

METHODS: This study was conducted on $\mathbf{1 1 6}$ patients who were admitted in Liaquat University Hospital. Case definition was high grade fever with leucopenia and thrombocytopenia.

RESULTS: Only 52 out of 116 patients were confirmed as having Dengue IgM antibodies. The highest sufferers of Dengue fever were young adults. Almost all cases developed mild to moderate thrombocytopenia and leucopenia. Most patients recovered spontaneously in less than 10 days. Only 3 patients expired.

CONCLUSION: Dengue fever is endemic in sub-Saharan region and in South Asia including Pakistan. Out-breaks occur from time to time. The current outbreak being the $3^{\text {rd }}$ episode in the last 13 years points towards the importance of comprehensive research for the prevention and control of the disease. Although case fatality rates are low however it must be considered as public health problem and serious efforts shall be undertaken for public awareness and vector control.
\end{abstract}

KEY WORDS: Dengue fever. Thrombocytopenia. Leucopenia. Mortality.

\section{INTRODUCTION}

Dengue virus is a tropical mosquito-borne flavivirus infecting more than 100 million humans each year. ${ }^{1}$ It is becoming an increasing public heath problem with being cause of over $99 \%$ cases of viral hemorrhagic fever. ${ }^{2}$ Majority of dengue infections cause a mild selflimiting febrile illness 'dengue fever (DF)', however some infections lead to potentially fatal dengue hemorrhagic fever (DHF) and the more severe dengue shock syndrome (DSS). ${ }^{3}$ DHF is the leading cause of hospitalization and death among children in many countries of Southeast Asia. An estimated $50-100$ million cases of dengue fever and several hundred thousand cases of dengue hemorrhagic fever occur each year. ${ }^{4,5}$ Dengue is endemic in Southeast Asia and Indian subcontinent and is also seen in the Africa. ${ }^{6}$ Dengue is transmitted by the mosquito vector Aedes aegypti and sometimes by Aedes albopictus, especially in Southeast Asia. ${ }^{4}$ There are four serotypes of dengue virus (DEN-1, DEN-2, DEN-3 and DEN-4), all producing a similar clinical syndrome. ${ }^{6}$ The incubation period ranges between 3 and 15 days, usually $7-10$ days. ${ }^{4}$ Clinical features are sudden onset of high fever, chills and aching of the head, back and extremities, pain on eye movements, relative bradycardia, lymphadenopathy, prostration and depression as well as continuation of biphasic fever curve. ${ }^{1,4}$ Initial phase of fever continues for 3-7 days then remission for few hours to two days, while second phase lasts for 1-2 days. Initially, the skin appears flushed but 3-4 days after the fever, a maculopapular rash starts appearing which characteristically spreads to palms and soles in over $50 \%$ of cases. Homotypic immunity is life long but heterotypic immunity between serotypes lasts only a few months. ${ }^{4}$ A secondary infection with another serotype may actually augment host reaction and result in a more severe or serious illness. ${ }^{7}$ Dengue fever was first noticed in 1950, while in Pakistan, the first outbreak of dengue fever was reported in 1994. Another outbreak was seen in $2005 .{ }^{2}$ This study describes the characteristics of suspected dengue patients seen at a tertiary care centre during the worst till date dengue outbreak in the history of Pakistan in the year 2006. There were a total of 40 reported deaths, of which 37 from the province of Sindh, making it the largest and most severe outbreak of dengue fever in the country. ${ }^{8}$ 


\section{PATIENTS AND METHODS}

This descriptive study was conducted at the outpatient clinics and medical wards of Liaquat University Hospital Hyderabad/ Jamshoro, Sindh - Pakistan between October and December 2006. Patients for the study were enrolled conveniently, and included those who were suspected or confirmed cases of dengue fever. All patients included had acute fever of less than 3 weeks duration with leucopenia (WBC count $<4000 / \mathrm{mm}^{3}$ ), thrombocytopenia (Platelets count $<100,000 / \mathrm{mm}^{3}$ ) and having no other explanation for fever and thrombocytopenia. Alternative causes of acute fever were ruled out by history, examination, complete blood picture, negative malarial parasites and typhidot IgM. Definite diagnosis was made by detection of IgM against dengue virus by ELISA on $10^{\text {th }}$ day of fever. Clotting profile and LFT were also checked where needed. The information including socio-demographic, clinical and laboratory data of patients was recorded on a proforma and the descriptive data analysis was done with the help of software SPSS 10.0.

\section{RESULTS}

During the three months period from October to December 2006, 116 suspected dengue patients presenting at Liaquat University Hospital were included in the study. Most of the patients presented during the month of November ( $n=57,49.1 \%)$. Males were predominantly affected by dengue infection as shown in Table I. Age range of patients was between 1 year and 65 years. When age was categorized, most of patients $(61.2 \%)$ were aged 15 years and above. Majority of patients $(70.7 \%)$ belonged to urban areas and remaining $29.3 \%$ were from rural areas. In 52 patients $(44.8 \%)$ dengue $\operatorname{lgM}$ antibody was positive and 64 $(55.2 \%)$ patients were sero-negative for dengue IgM antibody. Majority of the patients $(91,78.4 \%)$ were discharged after improvement in their condition, while $19.0 \%$ patients were severe and transferred to teaching hospitals in Karachi with more number of beds and better services for treating such patients. Our 12 patients received platelet transfusion and these were whom who had platelet count less than 10,000. Figure I shows range of platelet counts. Dengue fever complications led to three deaths $(2.6 \%)$ in this hospital. Among patients who died, two were suffering from DSS and third one had severe bleeding. (Figure II) All the patients presented with fever beside other symptoms. Majority of patients $(n=65,56 \%)$ presented with bodyache, $40(34.48 \%)$ had rash over the body, 15 patients $(13 \%)$ were having gum bleeding and only 10 patients $(8.6 \%)$ presented with gastrointestinal bleeding.
TABLE I:

\section{CHARACTERISTICS OF SUSPECTED DENGUE FEVER PATIENTS SEEN DURING 2006 DENGUE OUTBREAK IN OUR SETUP}

\begin{tabular}{|l|c|c|}
\hline \multicolumn{1}{|c|}{ Characteristics } & $\begin{array}{c}\text { Number of } \\
\text { Patients }\end{array}$ & Percentage \\
\hline Gender & 83 & 71.5 \\
Male & 33 & 28.5 \\
Female & & \\
\hline Age & 45 & 38.8 \\
$<15$ Years & 71 & 61.2 \\
$\geq 15$ Years & & \\
\hline Month of presentation & 35 & 30.2 \\
October & 57 & 49.1 \\
November & 24 & 20.7 \\
December & \\
\hline
\end{tabular}

FIGURE I:

\section{PLATELETS COUNTS IN PATIENTS}

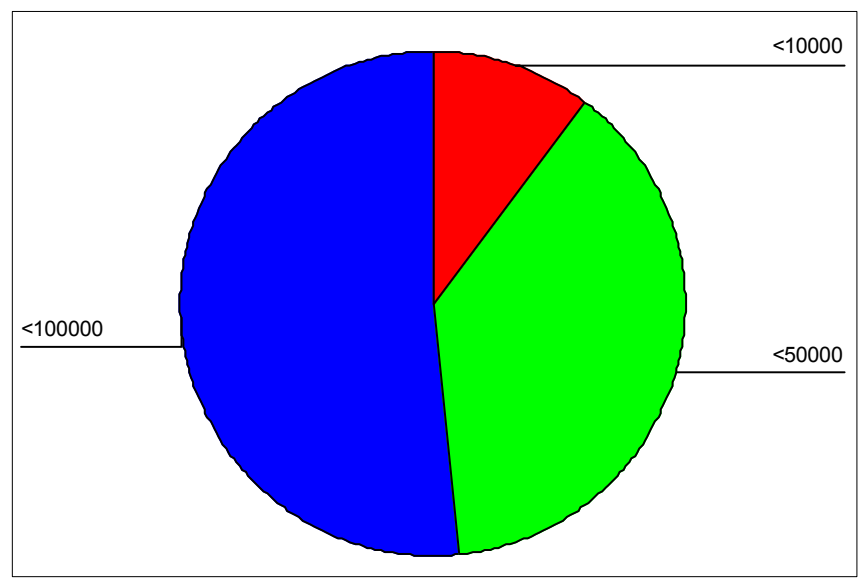

FIGURE II:

OUTCOME AND DENGUE IgM STATUS OF SUSPECTED DENGUE FEVER PATIENTS

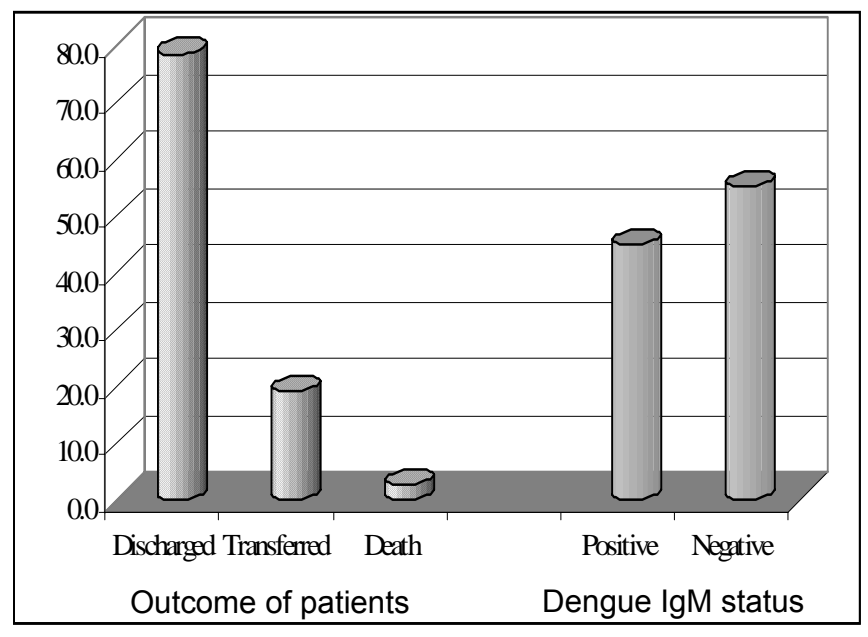




\section{DISCUSSION}

Dengue fever is an old disease, the first record of a clinically compatible disease being recorded in a Chinese medical encyclopedia in 265 to 420 A.D. In the aftermath of world war-II, rapid urbanization in Southeast Asia led to increased transmission and hyperendemicity. ${ }^{9}$ Dengue virus transmission has increased dramatically in the past 2 decades making this virus one of the most important mosquito borne pathogen. ${ }^{10}$ There has been a re-emergence of this disease in many tropical countries including India, Bangladesh and Pakistan. ${ }^{11}$ In this study, majority of patients were aged between 18 and 35 years with highest number at age of 30 years which is comparable to a study conducted in Jeddah, Saudi Arabia. ${ }^{12}$ This is contrary to other report which states that dengue mainly occurs in children less than 15 years of age. ${ }^{13}$ It may represent the fact that dengue infection is asymptomatic in $80 \%$ of infants and children. The illness is more severe and begins more suddenly in adults. ${ }^{4}$ Dengue virus causes a broad spectrum of illness ranging from mild undifferentiated fever to classical dengue fever, as well as dengue hemorrhagic fever and dengue shock syndrome. ${ }^{12}$ According to WHO definition, DHF can be differentiated from DF by leaking of plasma as manifested by homoconcentration, serous effusion or hypoproteinemia. DSS is the condition of circulatory failure with hypotension, cold clammy skin and restlessness and may be followed with profuse gastrointestinal bleeding. ${ }^{14}$ A rapid increase in the levels of cytokines and chemical mediators during dengue disease plays a key role in inducing plasma leakage, shock and hemorrhagic manifestations. ${ }^{15}$ Dengue virus has four serotypes I, II, III and IV. Each serotype produces life long immunity but provides, only short term cross immunity. The heterologous antibodies from previous infection act as a non-neutralizing antibody in any subsequent infection with a different serotype of the virus and form new complexes with the new infecting serotypes. These complexes can cause the antibody dependent enhancement of heterotypic secondary dengue infection. ${ }^{12}$ The enhancement of severe disease upon secondary infection makes dengue almost unique among infectious pathogens and presents a serious challenge to vaccine design. ${ }^{7}$ The clinical features in our patients apart from high grade fever were vomiting, abdominal pain, body aches in about $55 \%$ of cases which is again comparable to documented clinical features. ${ }^{3,9,12,13}$ Epistaxis, petechiae and gum bleeding were also noticed apart from the gastrointestinal bleeding. Maculopapular rash was found in 40 patients (34.5\%). Most of the patients improved and were discharged i.e. $78 \%$ while $19 \%$ were discharged and referred to Karachi for further management. Twelve patients recieved platelet transfusions. Pa- tients with bleeding were at higher risk to develop complications. Risky patients were monitored carefully for the sign and symptoms of shock. Dengue IgM was detected in $44.8 \%$ of patients, while it was not detected in $52.6 \%$ while missing in $2.6 \%$ cases. Second serum was not tested in non-detected dengue IgM patients because of various reasons including financial problems. This problem was also faced by other researchers. ${ }^{12,14}$ However, the clinical outcome of the positive or negative cases was not different; hence a presumptive diagnosis of dengue was maintained even in the negative cases.

There are no vaccines available against dengue virus, although several tetravalent live attenuated dengue vaccines are in clinical phase-I or II and prevention through vaccination has become a major priority on the agendas of $\mathrm{WHO}$ and national ministries of health. The NS3 protease domain of the NS3 protein is responsible for processing the viral poly protein and its inhibition is one of the principal aims of pharmacological therapy. ${ }^{15}$ Analysis of monthly dengue cases showed peak incidence in November 2006 ranging from October to December. This pattern is consistent with reports from other endemic countries ${ }^{11-13}$ and correlates well with the hot summer and monsoon season, which provides ideal breeding conditions for Aedes aegypti.

\section{CONCLUSION}

Dengue is a mosquito borne viral infection which in recent years has become a major public health problem. It is an acute febrile illness with manifestations ranging from asymptomatic to mild self limiting illness of short duration to grave bleeding tendencies and shock syndrome in rare occasion. In adults, males are affected at least twice than females. Most of the time patients recover spontaneously but disease can be fatal especially on secondary infection. At present, the only method of controlling or preventing dengue and DHF is to combat the vector i.e. mosquitoes.

\section{REFERENCES}

1. Halstead SB. Dengue. Curr Opin Infect Dis. 2002; 15(5):471-6.

2. Ali N, Nadeem A, Anwar M, Tariq WU, Chotani RA. Dengue fever in malaria endemic areas. J Coll Physicians Surg Pak. 2006;16(5):340-2.

3. Khan E, Siddiqui J, Shakoor S, Mehraj V, Jamil B, Hasan R. Dengue outbreak in Karachi, Pakistan, 2006: experience at a tertiary care center. Trans R Soc Trop Med Hyg 2007;101(11):1114-9.

4. Shandera W, Koo H. Infectious Diseases: Viral and Rickettsial. In: Mcphee JS, Papa dakis MA, Tierney Jr LM, eds. Current Medical Diagnosis and Treatment. 46 ed. New York: Mc GrawHill; 
2007; 1407-8.

5. WHO. Dengue and dengue haemorrhagic fever. Geneva: World Health Organization; 2002: Fact sheet No. 117.

6. Todd W, Lock Wood D, Sundar S. Infectious diseases. In: Boon NA. Colledge NR, Walker BR, Hunter JAA, eds. Davidson's Principles and Practice of Medicine. 20 ed. Edinburgh: Churchill Livingstone; 2006: 308 - 9.

7. Screaton G, Mongkolsapaya J. T cell responses and dengue haemorrhagic fever. Novartis Found Symp. 2006; 277:164-71; discussion 171-6, 2513.

8. Editorial. The News, Karachi Pakistan 2006 November 23.

9. Gubler DJ. Dengue/dengue haemorrhagic fever: history and current status. Novartis Found Symp 2006; 277: 3-16; discussion 16-22.

10. Rico-Hesse R. Dengue virus evolution and virulence models. Clin Infect Dis 2007; 44(11):1462-6.

11. Dash PK, Parida MM, Saxena P, Abhyankar A,
Singh CP, Tewari KN, et al. Reemergence of dengue virus type-3 (subtype-III) in India: implications for increased incidence of DHF and DSS. Virol J. 2006; 3:55.

12. Ayyub M, Khazindar AM, Lubbad EH, Barlas S, Alfi AY, Al-Ukayli S. Characteristics of dengue fever in a large public hospital, Jeddah, Saudi Arabia. J Ayub Med Coll Abbottabad 2006; 18 (2):9-13.

13. Kittigul L, Pitakarnjanakul P, Sujirarat D, Siripanichgon $\mathrm{K}$. The differences of clinical manifestations and laboratory findings in children and adults with dengue virus infection. J Clin Virol. 2007;39(2):76-81.

14. Salahuddin N, Ali F, Ali M, Rashid F. Dengue fever out break in Karachi, 2005 - A Clinical Experience. Infect Dis J. 2005;14(4):115-7.

15. Melino S, Paci M. Progress for dengue virus diseases. Towards the NS2B-NS3 pro inhibition for a therapeutic-based approach. Febs J. 2007;274 (12):2986-3002.

AUTHOR AFFILIATION:

Dr. M. Hanif Ghani

Assistant Professor, Department of Medicine

Liaquat University of Medical \& Health Sciences

(LUMHS) Jamshoro, Sindh-Pakistan.

\section{Dr. Mona Humaira}

Registrar, Department of Medicine

Liaquat University Hospital Jamshoro, Sindh-Pakistan.

\section{Dr. Imdad A. Khushk}

Deputy Director, Medical Research Centre

LUMHS Jamshoro, Sindh-Pakistan.

\section{Dr. Aslam Aziz Ghouri}

Registrar, Department of Medicine

Liaquat University Hospital Jamshoro, Sindh-Pakistan.

\section{Dr. Yasmeen Memon}

Senior Women Medical Officer, Department of Paediatrics

Liaquat University Hospital Jamshoro, Sindh-Pakistan.

\section{Dr. Mohammad Anwer Memon}

Professor, Department of Medicine

LUMHS Jamshoro, Sindh-Pakistan. 